\title{
Pattern of Growth Retardation and Sexual Maturation in Children having Beta Thalassaemia
}

\author{
Chhabra GS ${ }^{1}$, Sodhi MK ${ }^{2}$
}

${ }^{1}$ Gurpreet Singh Chhabra, MBBS, MD, Associate Professor, Department of Paediatrics, Sri Guru Ram Das Institute of Medical Sciences and Research, Amritsar, Punjab, India, ${ }^{2}$ Manmeet Kaur Sodhi, MBBS, MD, Associate Professor, Department of Paediatrics, Government Medical College, Amritsar, Punjab, India.

\section{Address for correspondence:}

Dr. Manmeet Kaur Sodhi, MBBS, MD

Associate Professor, Department of

Paediatrics,

Government Medical College, Amritsar,

Punjab, India

E-mail: doctor.manmeet@yahoo.com

Tel No; +977919888895499

Acknowledgements: None

Funding: Nil

Conflict of Interest: None

Permission from IRB: Yes

Ethical dilemmas faced during study: None

\section{How to cite}

Chhabra GS, Sodhi MK. Pattern of Growth Retardation and Sexual Maturation in Children having Beta Thalassaemia. J Nepal Paediatr Soc 2016;36(1):56-60.

doi: http://dx.doi.org/10.3126/jnps.v36i1.14479

This work is licensed under a Creative Commons Attribution 3.0 License.

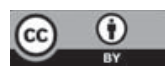

Key words: Growth retardation, serum ferritin, SMR thalassaemia.

\begin{abstract}
Introduction: Thalassaemia is a group of genetic disorders of blood, characterized by decreased synthesis of one of two types of poly peptide chain ( $\alpha$ or $\beta$ ) that form a normal adult human haemoglobin molecule ( $\mathrm{Hb} A-\alpha 2 \mathrm{~B} 2)$. This results in decreased filling of red cell with haemoglobin and anaemia. Retardation of growth and delayed sexual maturation can occur as a complication of thalassaemia. The objectives of this study were to study the pattern of growth failure and sexual maturity rate (SMR) in children with $\beta$-thalassaemia major, and to compare it with controls. Material and Methods: In this case-control study conducted simultaneously at two centres at Bebe Nanki Mother And Child Care Centre, Amritsar and Sri Guru Ram Das Charitable hospital, Amritsar, the growth parameters (height,weight and sexual maturation ) and serum ferritin levels of a total of 114 patients aged 8-16 years (64 males and 50 females) with $\beta$-thalassaemia major were compared with those of 100 healthy controls of the same age and gender. Results: Underweight was observed in $89(78.1 \%)$ of patient group and $9(9 \%)$ of control group. Short stature was observed in $64(56.1 \%)$ patients and $7(7 \%)$ of the control group. The mean age of menarche for female thalassaemia patients was $12.11 \pm 2.1$ years and for control females was $11.42 \pm 1.11$ years, The SMR were delayed in $108(95 \%)$ of patients and in $6(6 \%)$ of controls. The level of serum ferritin was found to be significantly associated with delayed SMR in thalassaemia patients. Conclusion: Growth failure and delayed SMR significantly occur in thalassaemia patients, when compared to the controls. Adequate chelation therapy can help in controlling serum ferritin levels and thereby facilitating normal physical growth and sexual development in chronically transfused thalassaemia patients.
\end{abstract}

\section{Introduction}

The thalassaemia are inherited disorders of Haemoglobin $(\mathrm{Hb})$ synthesis resulting from an alteration in globin chain production 
leading to impaired synthesis of the $\beta$ globins. The use of regular blood transfusions and chelation therapy with deferoxamine in the past few years has prolonged survival and transformed thalassaemia major from a fatal disease in early childhood to a chronic illness.

However, complications are still frequent and affect the patients' quality of life. There are multiple factors for retarded growth and delayed sexual development in thalassaemia patients. It includes chronic hypoxia secondary to anaemia and growth hormone insufficiency due to defective biosynthesis of somatomedin in the liver. Other factors contributing to the growth failure are decreased insulin-like growth factor1 (IGF1), sex steroid deficiency, hypogonadism, hypothyroidism. hypoparathyroidism and diabetes mellitus ${ }^{1,2}$.

Development of secondary sex characteristics in children with thalassaemia is markedly delayed than the expected development criteria, secondary to chronic hypoxia and iron overload ${ }^{3}$.

In thalassaemia major, multiple transfusions and inappropriately increased iron absorption associated with ineffective erythropoiesis leads to accumulation of iron. Threshold values for iron toxicity are serum ferritin $>2500 \mathrm{ng} / \mathrm{mL}$ and transferrin saturation $>75 \% .{ }^{4}$ (reference) When the iron-carrying capacity of transferrin is exceeded by the excessive and regular outpouring of catabolic iron, non-transferrin-bound iron starts to increase ${ }^{4}$.

Transfusion regimens maintaining pre-transfusion haemoglobin above 9-10 $\mathrm{gm} / \mathrm{dL}$ are effective in suppressing erythroid marrow expansion. Repeated transfusions in thalassemic patients and subsequent iron accumulation leads to complications including growth retardation, gonadal dysfunction, and delayed appearance of secondary sex characteristics ${ }^{5,6}$.

Using subcutaneous infusions of deferoxamine for at least 4-6 days a week reduces excessive iron and prevents cardiac, hepatic and endocrine diseases ${ }^{7,8}$. Growth failure has been attributed to growth hormone $(\mathrm{GH})$ deficiency (hypothalamic or pituitary), hypothyroidism, delayed sexual maturation, hypogonadism, diabetes mellitus, zinc deficit, low haemoglobin levels, bone disorders and deferoxamine toxicity.

The aim of this study was to evaluate the height, weight, gonadal function, and sex maturity rating, as well as their relationship to serum ferritin levels, in thalassemic patients and to compare it with controls.

\section{Material and Methods}

This was a cross-sectional, controlled study conducted at the Thalassaemia Wards of Bebe Nanki Mother and child Care Centre, Government medical college, Amritsar and the paediatric ward at Sri Guru Ram Das Charitable hospital, Amritsar. The objectives of this study were to determine growth parameters and pubertal development in patients with thalassaemia major, and to compare it with controls. The study was conducted over a period of six months from the 1st January 2015 to the $30^{\text {th }}$ June 2015.

A hundred and forty patients with thalassaemia are registered with the thalassaemia ward under Bebe Nanki Mother and Child Care Centre, Government medical college, Amritsar. Seventy eight (44 males and 34 females) children with $\beta$-thalassaemia major aged 8-16 years who attended thalassaemia ward during the study period were enrolled in this study.

About 58 patients of thalassaemia are registered with the paediatric department at Sri Guru Ram Das Charitable hospital, Amritsar. Thirty six (20 males and 16 females) patients with $\beta$-thalassaemia major, aged 8-16 years, who attended thalassaemia ward during the study period were enrolled in this study.

Cases of thalassaemia intermedia, thalassaemia minor and co-existent hypothyroidism were excluded from the study, after investigating for haemoglobin electrophoresis and thyroid function tests. Written consent was taken from parents of each child in the case and control groups, enrolled in this study.

Information was collected on a pre-designed questionnaire from parents of the patients via a faceto-face interview and included age, gender, residence, duration of thalassaemia, family history, and the age of onset of menarche.

Sexual maturity rating (SMR) was determined according to Tanner method ${ }^{9}$ using data collected by history taking and careful physical examination. Height and weight were measured by standard clinical methods. The Indian Academy of Paediatrics (IAP) growth curves were used as reference standards. Weight and height measurements were compared with the normal. For estimation of serum ferritin, $5 \mathrm{ml}$ venous blood samples were obtained between 8:30-9:00 a.m., by venipuncture, using plain tubes, and the samples were analyzed in laboratory.

A group of control matched for age and gender were selected from three schools chosen by simple random 
sampling (primary \& secondary schools) in Amritsar city. Before inclusion in the study, thalassaemia was ruled out in the control group by haemoglobin electrophoresis. Data were entered into Statistical Package for Social science (SPSS) program for Windows version I. The results were statistically analyzed by calculating the $p$-value. Statistical significance was set at 0.05 .

\section{Results}

In the present study, the age and gender of the patients are in between 8-16 years, males constitute 64 $(63 \%)$ and female $50(37 \%)$

The results of our study show that Underweight was observed in $89(78.1 \%)$ of patients as compared to $9(9.0 \%)$ of the control group, $(p$-value $=0.000)$, while Short stature were found in $64(56.1 \%)$ of patients and $7(7.0 \%)$ of controls ( $p$-value $=0.000)$, both of these parameters were of statistically significant.
In the present study, the SMR were delayed in $99(86.9 \%)$ of patients while it was delayed only in 6 $(6.0 \%)$ of controls of the same age and sex, this was statistically of high significance ( $p$-value $=0.00$ ).

Table 4 shows relation of serum ferritin levels with SMR rating and age of menarche. Out of 13 patients with serum ferritin levels less than $2000 \mathrm{mg} / \mathrm{dl}$, only 3 $(23.1 \%)$ showed delayed SMR. As the serum ferritin levels increased, the percentage of patients with delayed SMR increased significantly. All the patients (100\%) with ferritin above $5000 \mathrm{mg} / \mathrm{dl}$ showed delayed SMR.

Regarding the correlation of serum ferritin level and the onset of menarche in the present study, the age of onset of menarche was delayed in a total of 43 females, out of which 25 (58.1\%) of patients had serum ferritin level between 2000-5000mg/dl in comparison to $14(100 \%)$ of patients whose serum ferritin is more than $5000 \mathrm{mg} / \mathrm{dl}$ and this was statistically significant $(p$-value $<0.001)$.

Table 1: Age and gender distribution of the patients and controls

\begin{tabular}{ccccc}
\hline Gender & \multicolumn{2}{c}{ Study group $(\mathbf{n = 1 1 4 )}$} & \multicolumn{2}{c}{ Control group $(\mathbf{n}=100)$} \\
\hline Number & $\%$ & Number & $\%$ \\
\hline Female & 64 & 56.1 & 51 & 51.0 \\
\hline
\end{tabular}

Table 2: Weight and height percentiles of the patients and controls

\begin{tabular}{|c|c|c|c|c|c|}
\hline \multirow{2}{*}{$\begin{array}{l}\text { Variable } \\
\text { Weight (Kgs) }\end{array}$} & \multicolumn{2}{|c|}{ Study group $(n=114)$} & \multicolumn{2}{|c|}{ Control group $(n=100)$} & \multirow[b]{2}{*}{ p-value } \\
\hline & Number & Percentage (\%) & Number & Percentage (\%) & \\
\hline Less than $5^{\text {th }}$ percentile & 89 & $78.1 \%$ & 9 & 9.0 & $<0.001$ \\
\hline $5^{\text {th }}-95^{\text {th }}$ percentile & 55 & $21.9 \%$ & 84 & 84.0 & \\
\hline More than $95^{\text {th }}$ percentile & 0 & 0 & 7 & 7.0 & \\
\hline 2. Height (cms) & & & & & $<0.001$ \\
\hline Less than $5^{\text {th }}$ percentile & 64 & $56.1 \%$ & 7 & 7.0 & \\
\hline $5^{\text {th }}-95^{\text {th }}$ percentile & 50 & $43.9 \%$ & 91 & 91.0 & \\
\hline More than $95^{\text {th }}$ percentile & 0 & 0 & 2 & 2 & \\
\hline
\end{tabular}

Table 3: Distribution of SMR and menarche in patients and controls

\begin{tabular}{|c|c|c|c|c|c|}
\hline \multirow{2}{*}{$\begin{array}{l}\text { Variable } \\
\text { SMR }\end{array}$} & \multicolumn{2}{|c|}{ Study group (n?=114) } & \multicolumn{2}{|c|}{ Control group $(n ?=100)$} & \multirow{2}{*}{$\begin{array}{c}\text { Chi square } \\
p \text {-value }\end{array}$} \\
\hline & Number & $\%$ & Number & $\%$ & \\
\hline Appropriate for age & 15 & 13.1 & 94 & 94 & $<0.001$ \\
\hline Delayed for age & 99 & 86.9 & 6 & 6.0 & \\
\hline \multirow[t]{2}{*}{ Menarche } & \multicolumn{2}{|c|}{ Study Group (n=50) } & \multicolumn{2}{|c|}{ Control group (n=49) } & \\
\hline & Number & $\%$ & Number & $\%$ & $<0.001$ \\
\hline Normal & 7 & 14.0 & 44 & 89.8 & \\
\hline Delayed & 43 & 86.0 & 5 & 10.2 & \\
\hline
\end{tabular}


Table 4: Relation of variables of sexual maturation with serum ferritin levels

\begin{tabular}{|c|c|c|c|c|c|}
\hline \multicolumn{4}{|c|}{ SMR (males and females) } & \multicolumn{2}{|c|}{ Age of Menarche (females) } \\
\hline Serum Ferritin & Normal ( $n=16 ?)$ & Delayed ( $n=98 ?)$ & Serum ferritin & Normal $(n=7)$ & Delayed $(n=43)$ \\
\hline$<2000(n=13)$ & $10(\% ? 76.9 \%)$ & $3(23.1 \%)$ & $<2000(n=7)$ & $3(42.9 \%)$ & $4(57.1 \%)$ \\
\hline $2000-5000(n=71)$ & $6(8.4 \%)$ & $65(91.6 \%)$ & $2000-5000(n=29)$ & $4(13.8 \%)$ & $25(86.2 \%)$ \\
\hline$>5000(n=30)$ & $0(0 \%)$ & $30(100 \%)$ & $>5000(n=14)$ & $0(0 \%)$ & $14(100 \%)$ \\
\hline$P$ value & $<0.001$ & & & $<0.001$ & \\
\hline
\end{tabular}

\section{Discussion}

Table 2 compares the height and weight percentiles for the thalassaemia patients and controls. Many factors are responsible for short stature in patients with thalassaemia, the most important of which are dysfunction of the GH-IGF-I axis and desferoxamineinduced bone dysplasia. The patients of thalassaemia showed poor weight and height percentiles.

This observation is in concordance with previous studies across the world ${ }^{10,11,12}$, indicating that thalassaemia patients have risk factors for growth failure as a result from direct relation to iron toxicity especially on endocrine glands. Other important factors, contributing to growth failure are failure to initiate intensive chelation therapy below 10 years of age and other factors like anaemia, hypersplenism, Folate, Calcium and Zinc deficiency ${ }^{13,14,15}$. In a study by Gulati et al, height standard deviation (SD) score of patients $(-2.2 \pm 1.5)$ was significantly lower than that of normal controls $(-1.0 \pm 0.7, p<0.001)^{16}$.

Table 3 shows the distribution of sexual maturation in patients and controls. The SMR rating was assessed for both females and males, and details of menarche were compared among females. It is important to mention that some of the thalassaemia patients presented with complete lack of secondary sexual characters. This is consistent with other studies ${ }^{12,13}$. Hypogonadism is the most frequent endocrine complication, mostly due to gonadotrophins deficiency secondary to iron overload. Sex steroid treatment for induction of puberty and/or maintenance of sexual characteristics is necessary. In some patients absence of pubertal development is due to gonadotropin insufficiency, probably secondary to previous iron overload; other patients exhibit hypergonadotrophic hypogonadism due to the toxic effect of chemotherapeutic agents on the gonads. Both groups need hormonal replacement therapy.

Regarding the menarche, in the present study, the age of onset of menarche was delayed in 43 (86.0\%) of patients in comparison to $5(10.2 \%)$ of controls. This was statistically significant $(p$-value $=0.001)$ and similar to another study in which $74 \%$ of thalassaemia patients have delayed onset of menarche ${ }^{11}$. In a prospective study on Indian thalassaemia patients by Gulati et al, it was observed that 10 of 11 thalassaemia adolescents had hypogonadism ${ }^{16}$. On the other hand, in a study performed in an industrialized country, 28 out of 33 thalassaemia patients achieved normal puberty ${ }^{17}$.

Table 4 shows the relation of serum ferritn levels with delayed SMR and menarche. Serum ferritin was observed to be an independent direct marker for the delay in sexual maturation in both males and females. This is in concordance with other studies which concluded that patients with transfusion-dependent thalassaemia major tend to have abnormal growth and sexual maturation at puberty, presumably as a result of pituitary iron overload ${ }^{(18)}$.

Further, it was observed that $100 \%$ of thalassaemia with serum ferriitn levels above 5000 had delayed SMR scores, whereas only $23 \%$ of those with serum ferritin lower than 2000 had delayed SMR scores. Similar observations were made in the female thalassaemia patients. All females with ferritin above $5000 \mathrm{mg} / \mathrm{dl}$ levels showed delayed menarche (100\%).

This is in spite of newertransfusion regimens for betathalassaemia, where in the pre-transfusion haemoglobin concentration is not allowed to fall below $95 \mathrm{~g} / \mathrm{l}$. This allows adequate control of anaemia, with a relatively low rate of iron accumulation. Another study supports our result and concluded that high serum ferritin levels during puberty are a risk factor for hypogonadism, and high serum ferritin levels during the first decade of life predict final short stature ${ }^{19}$.

Multiple endocrinopathies, including hypogonadism, hypothyroidism and diabetes mellitus, occur mainly in patients who have high serum ferritin levels ${ }^{20}$. Prognosis for survival is greatly improved if the serum ferritin is kept below $2000 \mathrm{ng} / \mathrm{L}$ by regular chelation, in chronically transfused thalassaemia patients. 


\section{Conclusion}

We concluded that majority of children with $\beta$ thalassaemia major attending thalassaemia wards at both the centers had significant retardation of growth pattern and delayed sexual maturity. Also, high serum ferritin levels significantly contributed to delayed puberty

\section{References}

1. Aleem A, Al-Momen AK, Al-Harakati MS, Hassan A, Al-Fawaz I. Hypocalcemia due to hypoparathyroidism in $\beta$-thalassemia major patients. Ann Saudi Med 2000;20:364-66.

2. Engle MA. A cardiac involvement in Cooley's anaemia. Ann NY Acad Sci. 2002;119:694.

3. Anice G, Aparna B, Ved PC. Development of secondary sex characteristics in multitransfused thalassemic children. Ind J Ped 1997;64:855-59.

4. Dattani MT, Preece MA. Physical growth \& development. In: Farfar \& Arnells Textbook of Pediatrics, 5th edition; 1998:349-57.

5. Prati D. Benefits and complications of regular blood transfusion in patients with beta-thalassaemia major. Vox Sang 2000;79(3):129-37.

6. Kattamis AC, Antoniadis M, Manoli I, Kitra V, Petropoulos D, Grafakos S: Endocrine problems in exthalassemic patients. Transfus Sci 2000;23(3):251-52.

7. Jensen CE, Tuck SM, Old J, Morris RW, Yardumian A, De Sanctis V, Hoffbrand AV, Wonke B. Incidence of endocrine complications and clinical disease severity related to genotype analysis and iron overload in patients with beta thalassaemia. Eur $\mathrm{J}$ Haematol 1997;59(2):76-81.

8. Skordis N, Christou S, Koliou M, Pavlides N, Angastiniotis M. Fertility in female patients with thalassemia. J Pediatr Endocrinol Metab 1998;11:935943.

9. Behrman RE, KJiegman RM, Jenson HB: Nelson Textbook of Pediatrics, $16^{\text {th }}$ ed. Philadelphia: W.B. Saunders, pp.53-4, 2000.

10. Anita S. Growth retardation in thalassemia major patients. Int J Hum Genet 2003;3:237-46.

11. Roth C, Pekrun A, Bartz M, Jarry H, Eber S, Lakomek $M$, Schröter W. Short stature and Failure of pubertal development in thalassemia major: evidence for hypothalamic Neurosecretory dysfunction of growth in thalassaemia with multiple transfusions. Hence, it is recommended that proper and regular use of chelating agents in transfusion dependant patients can help them grow normally and attain puberty by maintaining ferritin levels within normal range. hormone secretion and defective pituitary gonadotropin secretion. Euro J Pediatr 1997;156:777.

12. Soliman A, Elzalabany M, Armer M, Ansari BM. growth and pubertal development in transfusion dependent children and adolescence with thalassemia major and sickle cell disease. Clin Endocrinol (oxf) 1995;42:581 86.

13. Borgna-Pignatti $C$, De Stefano $P$, Zonta L, Vullo C, De Sanctis V, Melevendi C, Naselli A, Masera G, Terzoli S, Gabutti V, et al. Growth and sexual maturation in thalassemia major. J Pedtr 1985;106:150-55.

14. Malik, Syed, Ahmed N. Complications in transfusion dependant patient of B-thalassemia major. Pak J Med Sci 2009;25:678 -82.

15. Heshmat M, Zohren O. Prevalence of growth and puberty Failure with respect to growth hormone and gonadotropins secretion in B-thalassemia Major. Arch Iranian Med 2006;9:329-34.

16. Galati R, Bhatia Y, Agawam SS. Early onset of endocrine abnormalities in beta-thalassemia major in a developing country. J Pediatr Endocrinol Metab 2000;13(6):651-56.

17. Berkovitch M, Bistritzer T, Milone SD, Perlman $\mathrm{K}$, Kucharczyk W, Olivieri NF: Iron deposition in the anterior pituitary in homozygous beta-thalassemia: MRI evaluation and correlation with gonadal function. J Pediatr Endocrinol Metab 2000;13(2):179-84.

18. Low LC: Growth, puberty and endocrine function in beta thalassaemia major. $J$ Pediatr Endocrinol Metab 1997;10(2):175-84.

19. Naomi B, Nancy F. Olivier, Beverley T, David F. Andrews, Melvin H. Freedman, and F. John H. Effect of Age at the Start of Iron Chelating Therapy on Gonad Function in $\beta$-Thalassemia Major. N Engl J Med 1990;323:713-19.

20. Shlomit S, Doron C, Naomi W, Moshe P, Hagit M, Liora $\mathrm{K}$, Rama Z, Isaac Y, Hannah T. Serum ferritin level as a predictor of impaired growth and puberty in thalassemia major patients. Euro J Haematol 2005;74(2): 93-100. 